\title{
DESENVOLVIMENTO E AVALIAÇÃO DE UM PROTÓTIPO CLASSIFICADOR DE TÁBUAS USANDO TÉCNICAS DE VISÃO ARTIFICIAL ${ }^{1}$
}

\author{
José Marcelo Gomes ${ }^{2}$, Francisco de Assis de Carvalho Pinto ${ }^{3}$, Ricardo Marius Della Lucia ${ }^{4}$ Joseph Kalil \\ Khoury Junior ${ }^{5}$
}

\begin{abstract}
RESUMO - A classe de qualidade de uma peça de madeira serrada é determinada pelos defeitos apresentados e por algumas características associadas a eles, como: dimensões da peça e dos defeitos, posição dos defeitos, quantidade e tipo. Os objetivos deste trabalho foram desenvolver e avaliar um protótipo para classificação de tábuas de madeira de eucalipto, com base em imagens digitais, composto por uma esteira rolante onde são inseridas as tábuas para obtenção das imagens de suas faces. O protótipo pode utilizar tanto a norma da Associação Brasileira de Normas Técnicas (ABNT) quanto a norma comercial de uma serraria. O processo pode ser acompanhado no microcomputador, que apresenta em seguida a imagem da tábua com o resultado final de sua classificação. A taxa de acerto no processo de classificação foi de $64,3 \%$, usando-se a norma da ABNT, e de $81,0 \%$ com o emprego da norma comercial. A produtividade do protótipo desenvolvido foi de $7,9 \mathrm{~m}^{3} \mathrm{~h}^{-1}$, na classificação de madeira serrada de eucalipto.
\end{abstract}

Palavras-chave: Processamento de imagens, classificação de tábuas e inspeção automatizada.

\section{DEVELOPMENT AND EVALUATION OF A PROTOTYPE TO CLASSIFY LUMBER USING ARTIFICIAL VISION TECHNIQUES}

\begin{abstract}
Lumber quality is determined by the defects presented and other characteristics such as: size, position, amount and type. The purpose of this research was to develop and evaluate a prototype to classify eucalyptus lumber using digital images. This prototype was built with a conveyor belt where the lumbers are inserted for image acquisition. Either the Brazilian standard (ABNT) or the commercial rule can be used for classification. The process can be followed in a microcomputer that shows the lumber image with its final grade. The overall accuracy rate in the classification process was $64.3 \%$ using the ABNT norm, and $81.0 \%$ percent using the commercial norm. Productivity of the developed prototype was $7.9 \mathrm{~m}^{3} \mathrm{~h}^{-1}$
\end{abstract}

Keywords: Image processing, lumber grading and web inspection.

\section{INTRODUÇÃO}

Uns dos fatores que afetam sensivelmente a produção de madeira serrada nos ambientes de serraria são os graduadores humanos, pois essa é uma atividade estressante, porque exige grande atenção por longos períodos de tempo. Os graduadores são aqueles trabalhadores das serrarias que observam as faces das tábuas para definir sua classificação em termos de qualidade. A qualidade de uma peça de madeira serrada é determinada por várias características dos defeitos que ela possui, como: dimensões da peça e dos defeitos, posição dos defeitos, quantidade e tipo (LEE et al., 2003). Quanto menos defeitos uma peça de madeira apresentar, maior o seu valor (LEITE et al., 2005).

\footnotetext{
${ }^{1}$ Recebido em 22.03.2007 e aceito para publicação em 22.08.2008.

${ }^{2}$ Colégio de Aplicação (COLUNI) da Universidade Federal de Viçosa (UFV). E-mail:<jmgsgsg@ yahoo.com.br>.

${ }^{3}$ Departamento de Engenharia Agricóla da UFV. E-mail:<facpinto@ufv.br>.

${ }^{4}$ Departamento de Engenharia Florestal da UFV. E-mail:<rdluica@ ufv.br $>$.

${ }^{5}$ Departamento de Engenharia de Produção e Mecânica da UFV. E-mail:<kalil@ufv.br>.
} 
Segundo Kline et al. (2003), os graduadores humanos possuem uma taxa de acerto na classificação em torno de $48,0 \%$. Portanto, um sistema automatizado para realização dessa tarefa tem margem grande para prover aumento na taxa de acerto, dado que o desempenho desses graduadores é relativamente baixo. Além disso, máquinas não são afetadas por fadiga ou estresse, que podem causar diminuição de rendimento.

Uma opção que tem sido objeto de estudo para automação do processo de classificação de madeira serrada é a utilização de um sistema de visão artificial (LU, 1997; KAUPPINEN, 1999). Os sistemas de visão artificial para inspeção de superfícies de peças de madeira são constituídos de três etapas: aquisição, processamento e análise de imagens. Na primeira etapa, utilizam-se os sensores ópticos para obtenção das cenas. A etapa de processamento da imagem tem como objetivo a segmentação e reconhecimento (identificação e medição) dos objetos de interesse. Na última etapa, a informação é transformada de sua forma de imagem digital para expressões que designam a classificação da peça da madeira como pertencente a dada classe ou peça a ser descartada.

Conners et al. (1989) conduziram estudos com o intuito de testar a possibilidade de uso de um sistema de visão artificial para localizar variações na superfície de madeira serrada. Três experimentos de análise de imagens digitais foram conduzidos para investigar métodos de segmentação e problemas causados pela variação de coloração da madeira. Concluiu-se que, naquela época, essa era uma tarefa difícil, pois exigia muito recurso computacional, porém viável, e pesquisa adicional.

Segundo Funk et al. (2003), pesquisas foram conduzidas no sentido de mostrar que o uso de imagens RGB poderia incrementar a diferenciação entre defeitos, em comparação com imagens em escala de cinza. Conseguiu-se melhorar em torno de $20,0 \%$ a taxa de acerto, mas foi observado que o aumento significativo na quantidade de informações fornecidas pelas cores aumentou também os desafios presentes no processo de análise, a exemplo do tempo de processamento.

Com o objetivo de melhorar a taxa de acerto alcançada por máquinas com apenas um sensor na classificação de madeira serrada, Kline et al. (2003) projetaram e construíram uma máquina com múltiplos sensores para essa tarefa. O protótipo possuía um mecanismo de leitura, que gerava imagens por meio de uma câmera RGB e dois mecanismos de geração de imagens, sendo um de raios $\mathrm{x}$ e outro de raios laser. O sistema alcançou resultados melhores do que os de graduadores humanos que realizaram a mesma tarefa, com as mesmas tábuas, na linha de produção. Os graduadores, em média, apresentaram uma taxa de acerto em torno de 48,0\%, enquanto a máquina de múltiplos sensores atingiu acerto de $63,0 \%$.

Alguns autores, com Khoury Junior et al. (2005), utilizaram a Análise de Componentes Principais (ACP), com o objetivo reduzir o número de variáveis a serem usadas no processo de classificação. Parte-se do princípio de que, combinando um conjunto de variáveis quaisquer, é possível construir um novo grupamento, menos numeroso de variáveis principais que resumam a informação contida no grupo inicial.

Sendo o número de variáveis originais igual a p, para se reproduzir a variabilidade total dos dados são necessários p componentes principais, mas, em geral, a maior parte dessa variabilidade se deve a um número $\mathrm{k}$ de componentes menor que $\mathrm{p}$. Assim, as $\mathrm{p}$ variáveis originais com $\mathrm{n}$ observações cada podem ser reduzidas a um conjunto com o mesmo número de observações, mas com apenas $\mathrm{k}$ componentes principais (JOHNSON e WICHERN, 1998).

$\mathrm{Na}$ ACP, os autovalores $\lambda_{i}$ da matriz $M_{c}$ e os seus correspondentes autovetores $e_{i}$ são calculados, sendo os componentes principais combinações lineares das $\mathrm{p}$ variáveis aleatórias $\left(\mathrm{x}_{1}, \mathrm{x}_{2}, \ldots, \mathrm{x}_{\mathrm{p}-1}, \mathrm{x}_{\mathrm{p}}\right)$. A proporção da variação total explicada pelos $\mathrm{k}$ primeiros componentes principais é obtida pela equação 1 :

$$
P_{\left(Y_{1-k}\right)}=\frac{\sum_{i=1}^{k} \lambda_{i}}{\sum_{j=1}^{p} \lambda_{j}}, k=1,2, \ldots, p
$$

em que $P_{\left(Y_{1-k}\right)}=$ proporção da variação total explicada pelos $\mathrm{k}$ primeiros componentes principais; $\mathrm{e} \lambda_{\mathrm{i}}=$ autovalores da matriz de co-variância $(1 \leq \mathrm{i} \leq \mathrm{p})$.

Quando a maior parte da variância estiver acumulada nos primeiros componentes principais, estes podem substituir as p variáveis originais sem muita perda de informação.

Khoury Junior et al. (2005) desenvolveram e testaram Redes Neurais Artificiais (RNA) para identificar defeitos 
em madeira serrada de eucalipto. Foram utilizadas as características de percentis das bandas RGB de imagens obtidas com câmeras coloridas. Os classificadores foram considerados satisfatórios na separação entre defeitos e madeira limpa e na identificação dos defeitos em madeira serrada dessa espécie.

Este trabalho teve como objetivos desenvolver e avaliar um protótipo para classificação de tábuas de madeira de eucalipto com base em um sistema de visão artificial. Foi desenvolvido um classificador de blocos de imagens para ser empregado na identificação e quantificação de defeitos em imagens de madeira serrada para sua posterior classificação, segundo as classes de qualidade da norma oficial da ABNT, NBR 14.806: Madeira serrada de eucalipto - Requisitos $2002 B$, e de uma norma comercial, da $A R A C R U Z$ PRODUTOS DE MADEIRA S.A., de 2004.

\section{MATERIAL E MÉTODOS}

Foi construído um protótipo de um sistema de visão artificial que simula a esteira transportadora de madeira serrada de uma indústria, de acordo com o esquema da Figura 1.

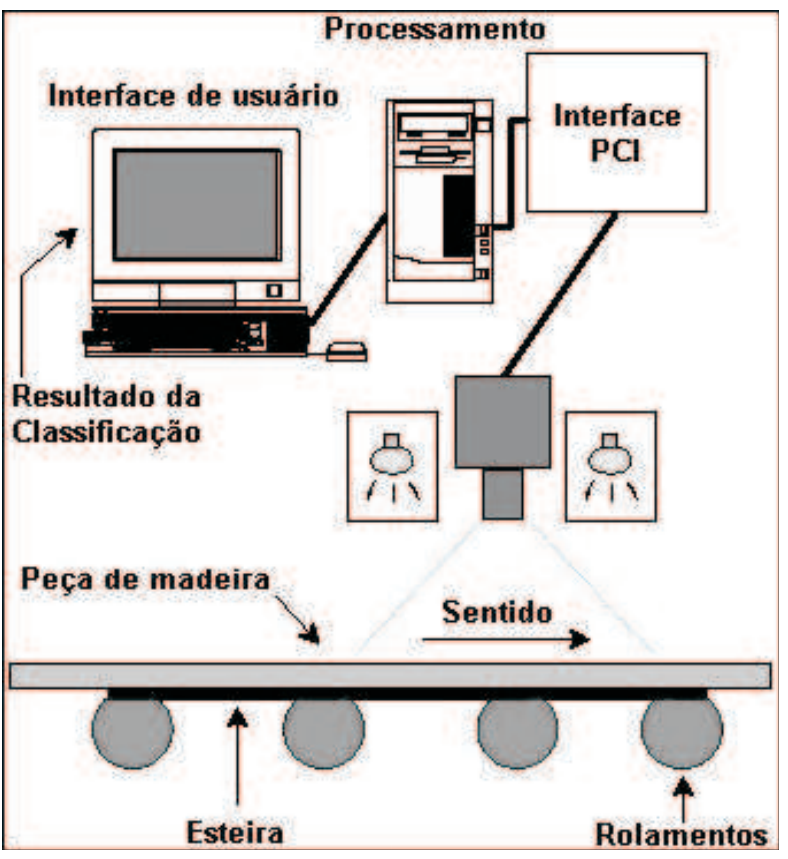

Figura 1 - Esquema do protótipo de classificação de madeira por sistema de visão artificial.

Figure 1 - Prototype scheme for sawn wood classification using a machine vision system.
O protótipo é composto por um sistema de aquisição de imagem superior e perpendicular ao deslocamento da tábua, com iluminação controlada, acoplada a uma placa de aquisição de vídeo instalada em um microcomputador. Ele possui uma esteira rolante, de 0,4 m de largura e 3,0 m de comprimento, com velocidade controlável. A esteira é impulsionada por um motor de indução trifásico de 0,7 kW (1 cv), da marca Eberle, modelo B80a4. A velocidade da esteira foi regulada para aproximadamente $0,6 \mathrm{~m} \mathrm{~s}^{-1}$, utilizando-se um inversor de freqüência da marca Yaskawa, modelo CIMRV7AA21P5.

As tábuas foram manualmente inseridas no protótipo sobre a esteira rolante. A esteira conduziu a tábua até a câmera que, por sua vez, captou a imagem desta, em partes, por meio do software desenvolvido utilizando-se a linguagem $\mathrm{C}++$. Um programa de computador foi desenvolvido, usando-se o programa Matlab $^{\circledR}$ versão 6.5, para montar a imagem final para posterior processamento. Depois de obtida a imagem de uma face da tábua, ela foi repassada no protótipo para aquisição da imagem da outra face, para iniciar sua classificação.

A iluminação foi feita por duas lâmpadas alógenas de $300 \mathrm{~W}$ instaladas em refletores com difusor de luz. As imagens foram obtidas, então, em condição de iluminação controlada. Foi montada uma estrutura metálica de 2,12 m de altura por 0,86 x 0,67 m de comprimento e largura, encapsulada por material plástico completamente opaco, que continha aberturas nas laterais esquerda e direita para a colocação dos refletores.

Uma câmera de vídeo digital, modelo CV-M7+/CL, colorida, foi acoplada ao computador pessoal, por meio de uma placa de aquisição de vídeo padrão CamLink (PULNIX, 2005). A lente utilizada foi uma CCTV 20HC, com distância focal de $25 \mathrm{~mm}, C C D$ de $2 / 3$ ”. A lente permite o controle manual do foco e da abertura do diafragma, e para a obtenção de imagens of-stop foi definido em 3,5. A câmera foi colocada a $0,9 \mathrm{~m}$ de altura, de modo a fornecer uma resolução de 0,24 x 0,24 mm/ pixels, conforme Kauppinen, (1999); Khoury Junior et al., (2005), que utilizaram configuração semelhante em sistemas de classificação de defeitos em madeira. Essa câmera permite aquisição de imagens RGB de $1.392(\mathrm{H}) \times 1.024(\mathrm{~V})$ pixels. Via software, o tempo de exposição do CCD foi ajustado para $1 / 800$ s. As imagens capturadas foram enviadas à memória principal para processamento.

R. Árvore, Viçosa-MG, v.32, n.5, p.949-959, 2008 
Além da linguagem $\mathrm{C}++$, foi utilizado o conjunto de bibliotecas de funções fornecidas pelo fabricante da câmera para o desenvolvimento do algoritmo de aquisição das imagens.

\subsection{Classificador estatístico}

Classificadores estatísticos são derivados do teorema de Bayes, no qual se determina a probabilidade a posteriori, $\mathrm{P}\left(\mathrm{C}_{\mathrm{j}} \mid \mathrm{v}\right)$, de que um indivíduo $\mathrm{v}$ seja classificado na classe $\mathrm{C}_{\mathrm{j}}$. A probabilidade a posteriori é obtida para cada uma das classes $\mathrm{C}_{\mathrm{j}}$, por meio do produto da probabilidade a priori de ocorrência da classe, $\mathrm{P}\left(\mathrm{C}_{\mathrm{j}}\right)$, pela probabilidade condicional da característica $\mathrm{v}$ dentro da classe $\mathrm{C}_{\mathrm{j}}, \mathrm{P}\left(\mathrm{v} \mid \mathrm{C}_{\mathrm{j}}\right.$ ). A probabilidade a priori $\mathrm{P}\left(\mathrm{C}_{\mathrm{j}}\right)$ pode ser estimada pela freqüência de ocorrência das classes na amostra. O indivíduo será classificado na classe que apresentar maior valor da probabilidade a posteriori $\mathrm{P}\left(\mathrm{C}_{\mathrm{j}} \mid \mathrm{v}\right)$.

Neste trabalho, assumiu-se uma co-variância comum em todas as classes, a qual foi obtida, ponderandose a matriz de co-variância individual de cada agrupamento em relação ao número de blocos amostrados em cada um dos agrupamentos. Assim, usou-se a equação 2, que é conhecida como função discriminante linear:

$D_{j}(v)=-\frac{1}{2} \bar{v}_{j}^{T}\left(M_{c}\right)^{-1} \bar{v}_{j}+v^{T}\left(M_{c}\right)^{-1} \bar{v}_{j}+\ln \left(P\left(C_{j}\right)\right)$

em que $\mathrm{D}_{\mathrm{j}}(\mathrm{v})$ = valor da função discriminante linear da classe $\mathrm{C}_{\mathrm{j}}$, dado $\mathrm{v}$; $\mathrm{v}=$ vetor de características de dado bloco; $\bar{v}_{j}=$ vetor de média das características da classe $\mathrm{C}_{\mathrm{j}}$; e $\mathrm{M}=$ matriz de co-variância comum das classes $\mathrm{C}_{\mathrm{j}}$.

Depois de determinados os valores de $\mathrm{D}_{1}(\mathrm{v}), \mathrm{D}_{2}(\mathrm{v}), \ldots$, $\mathrm{D}_{\mathrm{j}}(\mathrm{v})$ das $\mathrm{j}$ classes de defeitos da tábua, o maior desses valores ocorre onde o indivíduo $\mathrm{v}$ tem maior probabilidade de pertencer.

O classificador foi desenvolvido a partir de características extraídas de tábuas de eucalipto amostradas, secas ao ar livre, oriundas da ARACRUZ Celulose S.A. As amostras tiveram seus defeitos quantificados manualmente e foram etiquetadas, para obtenção das imagens. Das 53 tábuas obtidas, foram retiradas 11 amostras escolhidas que tivessem os defeitos visuais mencionados na Norma NBR 14.806 (ABNT, 2002B), segundo as definições da NBR 12.551 (ABNT, 2002A), a saber: bolsa de goma, esmoado, fendilhado, podridão, medula, nó cariado, nó solto encaixado, nó solto oco, racha na extremidade e furo de inseto.

Foram feitas simplificações na norma da ABNT com base em algumas das conclusões do trabalho de Khoury Junior et al. (2005) e análise das normas de classificação. Foram determinados para este trabalho os seguintes agrupamentos de classes:

Onze tábuas tiveram suas faces imageadas no protótipo, com a iluminação artificial controlada. Elas tiveram todos os seus defeitos identificados visualmente e recortados manualmente, usando-se o programa Gimp v2.2.8, da GNU Foundation. Foram utilizados blocos de 64 x 64 pixels. Os defeitos menores que um bloco foram recortados de modo a ocupar o bloco na sua posição central, e os maiores foram divididos em mais de um bloco. Um subconjunto dos blocos gerados foi usado para o desenvolvimento do classificador.

Calcularam-se, então, as características do histograma dos blocos da imagem original: média, mediana, desviopadrão e valores de percentil 2, 5, 10, 20, 30, 40, 50, 60, $70,80,90$ e $95 \%$ (KAUPPINEN, 1999). Essas 15 características foram calculadas para cada uma das bandas vermelho, verde e azul, totalizando um vetor-coluna com 45 características (ou descritores) para cada bloco.

Com o intuito de minimizar a diferença de iluminação entre as cenas, a diferença entre os percentis 2 e $95 \%$ foi utilizada para normalização do percentil de cada bloco, por meio da seguinte fórmula:

$$
C_{B}^{x}=-\frac{P_{B}^{x}}{P_{B}^{95}-P_{B}^{2}}
$$

em que $C_{B}^{x}=$ característica normalizada do percentil $\mathrm{x}$; = nível de cinza do percentil $\mathrm{x}$; e $\mathrm{x}=2,5,10,20$, $30,40,50,60,70,80,90$ e $95 \%$.

Quadro 1 - Agrupamentos definidos Table 1 - Defined groups

\begin{tabular}{lccccc}
\hline Agrupamento & 1 & 2 & 3 & 4 & 5 \\
\hline Classes & madeira limpa & $\begin{array}{c}\text { bolsa de goma, podridão, } \\
\text { nó cariado, nó solto oco, } \\
\text { nó solto encaixado }\end{array}$ & esmoado & fendilhado & nó sadio, \\
& & & nó sadio corrompido \\
\hline
\end{tabular}

R. Árvore, Viçosa-MG, v.32, n.5, p.949-959, 2008 
Nos agrupamentos pré-definidos foram utilizadas, no desenvolvimento do classificador, as quantidades de blocos mostradas no Quadro 2.

Foi, então, desenvolvido e testado um classificador estatístico de blocos das imagens com base no vetor de características v. Esse classificador foi composto de funções discriminantes no espaço das características (equação 2).

Os parâmetros gerados a partir desses blocos, para serem usados pelo classificador no cálculo dos valores das seis funções discriminantes, uma para cada agrupamento, foram: 1) vetor de características de cada bloco: v; 2) vetor de média das características de todos os blocos de cada agrupamento: $\bar{v}_{j}$; 3) matriz de co-variância comum dos agrupamentos: $M_{c}$; 4 ) inversa da matriz de co-variância comum dos agrupamentos: $\mathrm{M}_{\mathrm{c}}{ }^{-1}$.

Primeiramente, foram desenvolvidas funções discriminantes, utilizando-se as 45 características. Os blocos classificados como defeitos foram identificados, e para aqueles defeitos que apresentaram maior índice de confusão foi desenvolvido e utilizado outro processo discriminante, utilizando-se as características morfológicas e informações de posição.

\subsection{Eliminação de características por Análise de Componentes Principais}

Foi feita a padronização dos dados (média zero e variância 1), que é recomendada quando uma variável tem escala muito mais elevada de valores que outras, portanto teria influência grande nos primeiros componentes principais (JOHNSON e WICHERN, 1998).

AACP identificou o conjunto de variáveis potenciais para o descarte de características, classificando-as em ordem crescente de importância. As características menos importantes foram, então, eliminadas, uma a uma, e os parâmetros do classificador estatístico foram recalculados com as restantes. No momento em que a eliminação de uma delas causou a redução do acerto global, o processo foi interrompido. Dessa maneira, foram eliminadas apenas as características que não implicaram redução no valor do acerto global da classificação das tábuas.
Quadro 2 - Quantidade de blocos, por agrupamento, usados na fase de desenvolvimento

Table 2-Amount of blocks, per group, used in the developmental stage

\begin{tabular}{ccccccc}
\hline Agrupamento & 1 & 2 & 3 & 4 & 5 & 6 \\
\hline Blocos & 500 & 80 & 80 & 60 & 14 & 80 \\
\hline
\end{tabular}

\subsection{Processamento das imagens}

O processamento de imagens teve o objetivo de segmentar os objetos de interesse: fundo, madeira limpa e defeitos. O software desenvolvido em $\mathrm{C}++$ obtinha uma imagem da câmera e a salvava num drive virtual na memória RAM do computador. A partir daí, foi desenvolvido um software no Matlab que acessava as imagens, tornando a operação de leitura totalmente realizada via memória principal.

Esse software fazia a junção das imagens parciais para formação da imagem final da tábua. Depois foi retirada a parte da esteira, por meio do uso do limiar de soma de pixels para separação entre esteira e tábua, a saber: onde havia esteira na imagem, a soma dos pixels das colunas resultava valor pequeno; onde havia tábua, essa mesma soma aumentava de valor, pois parte do preto da esteira era substituída pela imagem da tábua, que era mais clara.

A imagem resultante foi, ainda, cortada de modo a ter seu número de pixels ajustado, tanto na largura quanto no comprimento, para um valor múltiplo de 64, que foi o tamanho de bloco adotado. Obteve-se, então, a imagem a ser submetida ao processo de identificação e quantificação de defeitos para posterior classificação.

A tarefa de localização dos prováveis defeitos foi realizada da seguinte maneira:

a) Limiarização da imagem da tábua, tornando pretos os prováveis defeitos e branca a madeira limpa.

b) Filtragem da imagem, em duas etapas:

- uma operação de abertura ${ }^{1}$, ou seja, uma erosão, ${ }^{2}$ para eliminação de conjuntos pequenos de pixels (que não representam defeitos na imagem original e, portanto, poderiam causar falso positivo), seguida de uma dilatação ${ }^{3}$ para que as informações relevantes, perdidas durante a erosão sobre os defeitos verdadeiros, fossem restauradas.

\footnotetext{
${ }^{1}$ Operação morfológica matemática que suaviza o contorno dos objetos da imagem, quebra ligações estreitas entre objetos e elimina ruídos menores que o elemento estruturante (matriz 3 x 3 ).

${ }^{2}$ Operação morfológica que reduz as dimensões dos objetos da imagem, elimina ruídos menores que o elemento estruturante (matriz 3 x 3 ) e quebra ligações estreitas entre objetos próximos.

${ }^{3}$ Operação morfológica que aumenta as dimensões dos objetos da imagem e preenche pequenos orifícios desses objetos.
} 
- uma filtragem mediana ${ }^{4}$ para eliminação dos pequenos conjuntos de pixels ainda restantes, que poderiam também causar falsos positivos.

c) Localização dos defeitos na imagem filtrada, percorrendo-se linha por linha sua. Uma vez localizado o defeito, era retirado da imagem original na forma de bloco.

d) Este bloco, com probabilidade maior de ser defeito e não madeira limpa, foi, então, submetido ao classificador estatístico para determinação de seu agrupamento.

No item C, testava-se se o defeito contido no bloco ocupava toda a sua largura ou altura. Se, sim, o processamento seguia para o item $\mathrm{D}$. Mas, caso contrário, era feita uma centralização do defeito no bloco antes que fosse retirado da imagem original.

\subsection{Reclassificação baseada em características morfológicas e informações de posição}

A reclassificação dos blocos visou corrigir os erros cometidos pelo classificador bayesiano. Depois de determinado o agrupamento de defeitos a que um bloco pertencia, eram verificadas propriedades de posição e morfológicas (eixo maior e menor) que cada agrupamento possuía, com o objetivo de confirmar sua classificação. Todos os blocos classificados como pertencentes aos agrupamentos 2, 3, 4 e 6 foram submetidos à reclassificação, por apresentar maiores porcentagens de confusão na classificação com características do histograma.

As características de posição foram consideradas em relação à imagem inteira da tábua. São elas: distância em relação à primeira linha da tábua, distância em relação à última linha da tábua, distância em relação à primeira coluna da tábua e distância em relação à última coluna da tábua. A seguir, são listadas as reclassificações implementadas:

- Defeitos do agrupamento 2 localizados nas extremidades superior ou inferior da tábua tiveram sua classificação alterada para agrupamento 6 .

- Defeitos do agrupamento 2 localizados nas extremidades direita ou esquerda da tábua tiveram sua classificação alterada para agrupamento 3 .
- Defeitos do agrupamento 3 localizados na região central da tábua tiveram sua classificação alterada para agrupamento 2 , se estivessem próximos das extremidades esquerda ou direita da tábua.

- Defeitos do agrupamento 3 localizados na região central da tábua tiveram sua classificação alterada para agrupamento 6 , se estivessem localizados próximos das extremidades superiores ou inferiores da tábua.

- Defeitos do agrupamento 4 localizados nas extremidades superiores ou inferiores da tábua tiveram sua classificação alterada para agrupamento 6 .

- Defeitos do agrupamento 6 que ocupavam mais em largura de um bloco do que em altura tiveram sua classificação alterada para agrupamento 2 .

- Defeitos do agrupamento 2, que ocupavam menos da metade da largura de um bloco, mas tomavam toda a extensão da altura, tiveram sua classificação alterada para agrupamento 6 .

\subsection{Avaliação do resultado da classificação de blocos}

Os blocos para teste do classificador estatístico foram blocos não utilizados na fase de desenvolvimento desse classificador, nas seguintes quantidades:

Os resultados da classificação dos blocos de imagens foram organizados em uma matriz de confusão (CONGALTON, 1991). Dessa matriz foi estimado o coeficiente Kappa pela equação 4:

$$
\hat{K}=\frac{n \sum_{i=1}^{j} x_{i i}-\sum_{i=1}^{j} x_{i T}-x_{T i}}{n^{2}-\sum_{i=1}^{j} x_{i T}-x_{T i}}
$$

em que $\hat{K}=$ estimativa do coeficiente Kappa; $\mathrm{x}_{\mathrm{ii}}=$ valor na linha i e coluna i da matriz de confusão; $x_{\mathrm{iT}}=$ total da linha $\mathrm{i} ; \mathrm{x}_{\mathrm{Ti}}=$ total da coluna $\mathrm{i} ; \mathrm{n}=$ número total de amostras; e $\mathrm{j}=$ número total de agrupamentos.

Quadro 3- Quantidade de blocos, por agrupamento, usados na fase de testes

Table 3 -Amount of blocks, per group, used in the test stage

\begin{tabular}{ccccccc}
\hline Agrupamento & 1 & 2 & 3 & 4 & 5 & 6 \\
\hline Blocos & 7781 & 368 & 697 & 175 & 34 & 278 \\
\hline
\end{tabular}

\footnotetext{
${ }^{4}$ Cada pixel de saída contém o valor mediano de sua vizinhança 5 x 5 da imagem de entrada.
} 


\subsection{Análise das imagens e classificação das tábuas}

A análise de imagens teve o objetivo de identificar a qual classe de interesse a tábua pertencia, utilizandose os critérios da norma ABNT, NBR 14.806/2002B e da norma comercial, ARACRUZ/2004.

Dois algoritmos de classificação de cada face da tábua foram implementados e testados com base nas regras de cada uma das normas citadas. A classificação da tábua foi igual à classificação da sua pior face. Uma amostra de 42 tábuas, não usadas em nenhuma das etapas anteriores, foi submetida ao protótipo, para posterior comparação de resultados, com a finalidade de se obter, em porcentagem, a exatidão global do sistema, por meio da matriz de confusão para ambas as normas, com e sem o uso de reclassificação.

\section{RESULTADOS E DISCUSSÃO}

\subsection{Parâmetros do classificador estatístico}

Ao se tentar calcular a inversa da matriz de covariância comum, obteve-se como resposta que a matriz era mal condicionada. Portanto, foi calculada a inversa de Moore-Penrose (MATLAB, 2000) dessa matriz para ser utilizada pelo classificador.

As probabilidades a priori foram obtidas após a retirada de todos os blocos de defeito e madeira limpa das 11 tábuas e realização de agrupamentos. Os valores determinados foram: $83,4 \%$ para agrupamento $1 ; 3,9 \%$ para agrupamento $2 ; 7,5 \%$ para agrupamento $3 ; 1,9 \%$ para agrupamento $4 ; 0,4 \%$ para agrupamento 5 ; e $2,9 \%$ para agrupamento 6 .

\subsection{Eliminação de Variáveis Originais por Análise de Componentes Principais}

Cada característica proposta para descarte na ACP foi eliminada isoladamente, e os parâmetros do classificador estatístico foram recalculados, considerando-se as características restantes, e a classificação das tábuas foi novamente realizada utilizando a norma comercial.

As características do percentil 95 da banda verde, percentil 95 da banda vermelha e percentil 2 da banda azul foram eliminadas sem que houvesse diminuição do acerto global $(81,0 \%)$, obtido usando as 45 características originais. Neste trabalho, optou-se por eliminar apenas essas três, das 29 características indicadas para descarte pela ACP, por não causarem perda no acerto global. As outras 26 características indicadas não foram eliminadas porque causavam perda no acerto global sem ganho no desempenho do sistema, em termos de velocidade de processamento.

\subsection{Resultado da classificação de blocos de imagens}

No Quadro 4 é apresentada a matriz de confusão gerada para os blocos de imagens usados no teste final do classificador estatístico.

Pode-se observar que o agrupamento que teve o pior desempenho na classificação (erro de omissão de $67,7 \%$ ) foi o de número 5. O fator que contribuiu para esse índice foi a pequena ocorrência desses defeitos nas tábuas, o que causou dificuldade ao classificador em reconhecer tais blocos. O alto valor do erro de inclusão para esse mesmo agrupamento $(73,2 \%)$ se deveu ao fato de que ele possuía poucas instâncias amostradas, portanto poucas classificações de defeitos de outros agrupamentos no agrupamento 5 aumentavam significativamente a taxa de erro.

Quadro 4 - Matriz de confusão para blocos de imagens de defeitos das tábuas Table 4-Confusion matrix for lumber defect image blocks

\begin{tabular}{ccccccccc}
\hline Agrupamentos & 1 & 2 & 3 & 4 & 5 & 6 & Total & Erro Inclusão(\%) \\
\hline $\mathbf{1}$ & $\mathbf{7 7 6 8}$ & 4 & 87 & 2 & 13 & 3 & 7877 & $1,4 \%$ \\
$\mathbf{2}$ & 0 & $\mathbf{1 8 2}$ & 33 & 3 & 0 & 33 & 251 & $27,5 \%$ \\
$\mathbf{3}$ & 1 & 45 & $\mathbf{5 6 3}$ & 0 & 0 & 15 & 624 & $9,8 \%$ \\
$\mathbf{4}$ & 8 & 57 & 0 & $\mathbf{1 4 7}$ & 6 & 45 & 263 & $44,1 \%$ \\
$\mathbf{5}$ & 3 & 5 & 1 & 17 & $\mathbf{1 1}$ & 4 & 41 & $73,2 \%$ \\
$\mathbf{6}$ & 1 & 75 & 13 & 6 & 4 & $\mathbf{1 7 8}$ & 277 & $35,7 \%$ \\
\hline Total & 7781 & 368 & 697 & 175 & 34 & 278 & Total & Acerto Global \\
\hline Erro Omissão(\%) & $0,2 \%$ & $50,5 \%$ & $19,2 \%$ & $16,0 \%$ & $67,7 \%$ & $36,0 \%$ & $\mathbf{9 3 3 3}$ & $\mathbf{9 4 , 8 \%}$ \\
\hline
\end{tabular}


Entre os agrupamentos que representaram defeitos (2 a 5), o melhor resultado observado foi no agrupamento 4, que teve um erro de omissão de 16,0\%. Mas houve um erro de inclusão significativo: $44,1 \%$. Esse valor se deveu ao fato de algumas partes dos defeitos "bolsa de goma e podridão" (do agrupamento 2 ) e "racha" (do agrupamento 6), ao serem transformados em blocos, se assemelharem a um "fendilhado," o que tornou difícil a discriminação entre eles. Como tanto "fendilhado" como "bolsa de goma e podridão" podem ocorrer em qualquer parte da tábua, as regras de posição usadas na reclassificação, durante a classificação de tábuas, não podem oferecer possibilidade de diferenciação entre esses defeitos.

$\mathrm{O}$ agrupamento 2 teve o segundo maior erro de inclusão $(50,6 \%)$. Ele recebeu instâncias do agrupamento 3, que inclui o defeito "esmoado." Esse defeito, quando ocupa todo o bloco, possui características semelhantes à "bolsa de goma" (do agrupamento 2), tornando-os pouco diferenciáveis. Como tanto "esmoado" quanto "bolsa de goma" podem ocorrer nas extremidades de uma tábua, as regras de posição usadas na reclassificação não teriam a possibilidade de contribuir para a diferenciação entre eles.

Um baixo erro de inclusão (1,9\%) no agrupamento 1 ("madeira limpa") foi importante para o processo de classificação de tábuas, pois inclusões nesse agrupamento causariam classificações em classes abaixo das suas verdadeiras classes de qualidade. O erro de inclusão no agrupamento $2(27,5 \%)$ foi apenas aceitável. Inclusões nesse agrupamento causaram classificações de tábuas em classes inferiores, pois nele está incluso o defeito "bolsa de goma". A presença desse defeito por si só, segundo a norma daABNT, NBR 14.806/2002B, já causaria a classificação das tábuas em classes inferiores.
O valor do Kappa de 0,82 indicou eficiência no processo de classificação dos blocos.

Quanto à reclassificação dos blocos pelas características morfológicas e de posição, aproximadamente $71,0 \%$ implicou correção. Mas em outra parte dos reclassificados, $29,0 \%$, houve o problema inverso, pois havia recebido classificação correta e sofreu alteração para uma classificação errada. Observouse, então, que o número de alterações corretas foi maior que o de alterações para classificações incorretas, justificando o processo de reclassificação.

\subsection{Resultados da classificação de tábuas}

Devido à ausência de exemplares de tábuas para certas classes, não foi usado o coeficiente Kappa na avaliação das matrizes de confusão, nem na comparação entre elas. Portanto, a avaliação individual de cada matriz e a comparação entre elas foram feitas utilizandose o acerto global e os erros de omissão e de inclusão nas classes.

Nos Quadros 5 e 6, apresentam-se os resultados de classificação das tábuas, utilizando-se a norma da ABNT, NBR 14.806/2002B, sem e com a reclassificação, respectivamente.

A classe 5 teve o maior erro de omissão $(50,0 \%)$, sendo parte das suas amostras atribuída a classes superiores. Essa classificação foi devida à presença de "furo de inseto" em algumas delas. O "furo de inseto" é um defeito de dimensões muito pequenas que foi eliminado nas filtragens. Mas a presença dele em uma tábua, segundo a norma da ABNT, NBR 14.806/2002B, faz que ela só possa ser classificada nas classes mais inferiores, 5 ou 6 . Com a retirada do defeito na etapa de filtragem, as tábuas foram classificadas em classes superiores.

Quadro 5 - Matriz de confusão de imagens das tábuas classificadas pela norma da ABNT NBR 14.806/2002B, sem o uso da reclassificação dos blocos

Table 5 - Confusion matrix for classified lumber images using the Brazilian standard NBR 14.806/2002B, without reclassification

\begin{tabular}{|c|c|c|c|c|c|c|c|c|}
\hline Classes ABNT & 1 & 2 & 3 & 4 & 5 & 6 & Total & Erro de Inclusão(\%) \\
\hline 1 & $\mathbf{0}$ & 0 & 0 & 0 & 0 & 0 & $\mathbf{0}$ & $0,0 \%$ \\
\hline 2 & 0 & 8 & 0 & 0 & 2 & 0 & 10 & $20,0 \%$ \\
\hline 3 & 0 & 0 & $\mathbf{0}$ & 0 & 2 & 0 & 2 & $100 \%$ \\
\hline 4 & 0 & 1 & 0 & 3 & 5 & 0 & 9 & $66,7 \%$ \\
\hline 5 & 0 & 1 & 0 & 2 & 12 & 0 & 15 & $20,0 \%$ \\
\hline 6 & 0 & 0 & 0 & 0 & 3 & 3 & 6 & $50,0 \%$ \\
\hline Total & 0 & 10 & 0 & 5 & 24 & 3 & Total & Acerto Global \\
\hline Erro de Omissão(\%) & $0,0 \%$ & $20,0 \%$ & $0,0 \%$ & $40,0 \%$ & $50,0 \%$ & $0,0 \%$ & 42 & $61,9 \%$ \\
\hline
\end{tabular}

R. Árvore, Viçosa-MG, v.32, n.5, p.949-959, 2008 
Quadro 6 - Matriz de confusão de imagens das tábuas classificadas pela norma da ABNT NBR 14.806/2002B, com o uso da reclassificação dos blocos

Table 6 - Confusion matrix for classified lumber images using the Brazilian standard NBR 14.806/2002B, with reclassification

\begin{tabular}{ccccccccc}
\hline Classes ABNT & 1 & 2 & 3 & 4 & 5 & 6 & Total & Erro de Inclusão(\%) \\
\hline $\mathbf{1}$ & $\mathbf{0}$ & 0 & 0 & 0 & 0 & 0 & $\mathbf{0}$ & $0,0 \%$ \\
$\mathbf{2}$ & 0 & $\mathbf{9}$ & 0 & 0 & 2 & 0 & $\mathbf{1 1}$ & $18,2 \%$ \\
$\mathbf{3}$ & 0 & 0 & $\mathbf{0}$ & 1 & 5 & 1 & $\mathbf{7}$ & $100 \%$ \\
$\mathbf{4}$ & 0 & 0 & 0 & $\mathbf{3}$ & 3 & 0 & $\mathbf{6}$ & $50,0 \%$ \\
$\mathbf{5}$ & 0 & 1 & 0 & 1 & $\mathbf{1 3}$ & 0 & $\mathbf{1 5}$ & $13,3 \%$ \\
$\mathbf{6}$ & 0 & 0 & 0 & 0 & 1 & $\mathbf{2}$ & $\mathbf{3}$ & $33,3 \%$ \\
\hline Total & 0 & 10 & 0 & 5 & 24 & 3 & Total & Acerto Global \\
\hline Erro de Omissão(\%) & $0,0 \%$ & $10,0 \%$ & $0,0 \%$ & $40,0 \%$ & $45,8 \%$ & $33,3 \%$ & $\mathbf{4 2}$ & $\mathbf{6 4 , 3 \%}$ \\
\hline
\end{tabular}

Algumas tábuas classificadas como classe 5, mas que eram classe 6 , receberam essa designação devido ao tamanho do "esmoado" nelas presente. Este ocupava mais que 70,0\% do comprimento da tábua. Porém, durante a retirada da esteira da imagem da tábua, consumiase um pequeno pedaço deste devido à sua semelhança, em sua região de fronteira, com a esteira. Restava, então, uma tábua cuja largura e comprimento, em pixels, eram valores não múltiplos de 64. Fazia-se, depois, a retirada de tantas colunas e linhas quanto fossem necessárias para que a imagem fosse transformada, na largura e comprimento, em um valor múltiplo de 64 , que foi o tamanho do bloco adotado. Consumia-se, assim, mais uma pequena parte do "esmoado". Desse modo, o defeito sofria redução, e a tábua subia de classificação.

Oerro de inclusão da classe 3 foi máximo(100\%), porque não havia amostras para essa classe. Qualquer que fosse o valor da inclusão nela, o resultado seria o mesmo.

Nos Quadros 7 e 8, apresentam-se os resultados de classificação das tábuas, utilizando a norma comercial, da ARACRUZ/2004, sem e com a reclassificação, respectivamente.

No Quadro 7, pode-se observar o mesmo problema ocorrido no Quadro 5, que é causado pela amostra. O erro de inclusão da classe 3 foi máximo (100\%), porque não havia amostras para essa classe.

Outro problema com a amostra pode ser verificado aqui devido à ausência de tábuas classe 1. Não houve inclusão nessa classe, pois todas as tábuas utilizadas eram menores que o comprimento mínimo $(2,44 \mathrm{~m})$ para se enquadrar nela pela norma comercial. Assim, o algoritmo de classificação descartava logo a entrada de alguma tábua nessa classe, sem nem mesmo se utilizar a quantificação dos defeitos nela existentes.

A norma de classificação da $A R A C R U Z / 2004$ aceita tábuas com "furo de inseto" em todas as suas classes, mas essas tábuas precisam ter diâmetro menor que 0,635 mm. Tábuas com "furo de inseto" acima desse diâmetro recebem classificação 5. Como esse defeito foi eliminado na filtragem, havia tábuas classe 5 que foram classificadas em classes superiores.

O mesmo problema de classificação em classes superiores foi observado na norma da ABNT, NBR $14.806 / 2002 \mathrm{~B}$, com elementos da classe 6 indo para a classe 5 e desta para a classe 4 , por causa da retirada em excesso do "esmoado."

Quadro 7 - Matriz de confusão de imagens das tábuas classificadas pela norma comercial ARACRUZ/2004, sem o uso da reclassificação dos blocos

Table 7 - Confusion matrix for lumber images classified by the commercial norm ARACRUZ/2004, without reclassification

\begin{tabular}{|c|c|c|c|c|c|c|c|}
\hline Classes ARACRUZ & 1 & 2 & 3 & 4 & 5 & Total & Erro de Inclusão(\%) \\
\hline 1 & $\mathbf{0}$ & 0 & 0 & 0 & 0 & $\mathbf{0}$ & $0,0 \%$ \\
\hline 2 & 0 & 17 & 0 & 5 & 0 & 22 & $22,7 \%$ \\
\hline 3 & 0 & 0 & $\mathbf{0}$ & 2 & 0 & 2 & $100 \%$ \\
\hline 4 & 0 & 1 & 0 & 10 & 2 & 13 & $23,1 \%$ \\
\hline 5 & 0 & 0 & 0 & 2 & 3 & 5 & $40,0 \%$ \\
\hline Total & 0 & 18 & 0 & 19 & 5 & Total & Acerto Global \\
\hline Erro de Omissão(\%) & $0,0 \%$ & $5,6 \%$ & $0,0 \%$ & $47,4 \%$ & $40,0 \%$ & 42 & $71,4 \%$ \\
\hline
\end{tabular}


Quadro 8 - Matriz de confusão de imagens das tábuas classificadas pela norma comercial ARACRUZ/2004 e com o uso da reclassificação

Table 8 - Confusion matrix for lumber images classified by the commercial norm ARACRUZ/2004, with reclassification

\begin{tabular}{|c|c|c|c|c|c|c|c|}
\hline Classes ARACRUZ & 1 & 2 & 3 & 4 & 5 & Total & Erro de Inclusão(\%) \\
\hline 1 & $\mathbf{0}$ & 0 & 0 & 0 & 0 & $\mathbf{0}$ & $0,0 \%$ \\
\hline 2 & 0 & 14 & 0 & 1 & 1 & 16 & $12,5 \%$ \\
\hline 3 & 0 & 2 & $\mathbf{0}$ & 0 & 0 & 2 & $100 \%$ \\
\hline 4 & 0 & 2 & 0 & 17 & 1 & 20 & $15,0 \%$ \\
\hline 5 & 0 & 0 & 0 & 1 & 3 & 4 & $25,0 \%$ \\
\hline Total & 0 & 18 & 0 & 19 & 5 & Total & Acerto Global \\
\hline Erro de Omissão(\%) & $0,0 \%$ & $22,2 \%$ & $0,0 \%$ & $10,5 \%$ & $40,0 \%$ & 42 & $81,0 \%$ \\
\hline
\end{tabular}

A exatidão global na classificação de blocos foi alta $(94,8 \%)$, o que não se refletiu na classificação das tábuas $(64,3 \%$ e $81,0 \%$ para as normas ABNT, $N B R$ $14.806 / 2002 B$, e comercial, $A R A C R U Z / 2004)$. Isso ocorre porque, segundo a norma da ABNT, se uma tábua possui “bolsa de goma," ela só pode ser classificada como classes 4, 5 ou 6 . Como o número de tábuas utilizadas no teste do protótipo, que foi de 42 , foi bem menor que o número de blocos utilizados no teste do classificador, que foi de 9333, um erro desse tipo foi representativo no processo de classificação de tábuas, mas não pode ser dito no processo de classificação de blocos.

Na comparação entre os Quadros 5 e 6, com os resultados de classificação pela norma da $\mathrm{ABNT}, N B R$ $14.806 / 2002 B$, pode-se verificar que a reclassificação fez o acerto global subir de $61,9 \%$ para $64,3 \%$. Já comparando os Quadros 7 e 8 com os resultados de classificação via norma comercial, ARACRUZ/2004, vê-se que a reclassificação fez o acerto global subir de $71,4 \%$ para $81,0 \%$. A reclassificação foi considerada útil, uma vez que teve influência positiva no índice final de acerto de classificação das tábuas.

\subsection{O comportamento funcional do protótipo}

O protótipo apresentou vibração na esteira quando em velocidade maior que $0,6 \mathrm{~m} \mathrm{~s}^{-1}$. Em velocidades mais elevadas, o contato da esteira com as laterais do protótipo fez que a vibração se tornasse fator limitante. Com relação à câmera, essa velocidade poderia aumentar, bastando ajustar o tempo de leitura do CCD.

Desconsiderando o tempo de virar a tábua e considerando uma tábua média como de 0,03 x 0,12 x 1,83 m de espessura, largura e comprimento, respectivamente, e a velocidade de operação de $0,6 \mathrm{~m} \mathrm{~s}^{-1}$, o protótipo teve produtividade aproximada de $7,9 \mathrm{~m}^{3} \mathrm{~h}^{-1}$.

R. Árvore, Viçosa-MG, v.32, n.5, p.949-959, 2008

\section{CONCLUSÕES}

O desempenho do classificador bayesiano mostrouse eficiente na classificação de blocos de imagens de madeira serrada. $\mathrm{O}$ índice Kappa foi de 0,82 e o acerto global, 94,8\%.

A reclassificação de blocos com base em características morfológicas e de posição trouxe resultados positivos ao processo de classificação de tábuas. Para a norma da ABNT, NBR 14.806/2002B, o resultado na classificação sem o uso de reclassificação foi de $61,9 \%$ e com o uso de reclassificação foi de $64,3 \%$, representando um ganho de $3,86 \%$ no índice de acerto. Para a norma comercial, ARACRUZ/2004, o resultado da classificação das tábuas sem o uso da reclassificação, de $71,4 \%$ e com o uso da reclassificação, de $81,0 \%$, proporcionando um ganho de $13,3 \%$ de acerto na classificação.

Normas menos complexas que a da ABNT, NBR $14.806 / 2002 \mathrm{~B}$, como as normas comerciais criadas por serrarias, como a da ARACRUZ/2004, facilitaram o processo de classificação e melhoraram a taxa de acerto.

O uso de uma esteira mais estreita no protótipo permitirá a solução do problema da vibração, podendose, assim aumentar sua velocidade para obter maior produtividade. A substituição da "AreaScan Camera" por uma "LineScan Camera", adequada para tarefa de inspeção em esteira rolante, aumentaria a eficiência no processo de obtenção das imagens.

O protótipo desenvolvido teve produtividade considerada satisfatória $\left(7,9 \mathrm{~m}^{3} \mathrm{~h}^{-1}\right)$ para ser utilizado na linha de produção de uma serraria comercial. 


\section{REFERÊNCIAS}

ARACRUZ PRODUTOS DE MADEIRA S.A. Descrição do produto - Madeira serrada de eucalipto. Disponível em: <http:// www.lyptus.com.br>. Acesso em: 9 ago., 2004.

\section{ASSOCIAÇÃO BRASILEIRA DE NORMAS} TÉCNICAS - ABNT. NBR 12.551: Madeira serrada - Terminologia. Rio de Janeiro: 2002a.

\section{ASSOCIAÇÃOBRASILEIRADENORMAS}

TÉCNICAS - ABNT. NBR 14.806: Madeira serrada de eucalipto - Requisitos. Rio de Janeiro: 2002b.

CONGAlton, R. G. A review of assessing the accuracy of classifications of remotely sensed data. In: REMOTE sensing thematic accuracy assessment: a compendium. Las vegas: Lynn K. Fenstermaker, 1991. p.3-14.

CONNERS, R. W.; CHO, T. H.; ARAMAN, P. A. Lumber grading with a computer vision system. In: ANNUAL HARDWOOD SYMPOSIUM, 7., 1989, Merrimac. Annals... Wisconsin: 1989. p.182-193.

FUNCK, J. W. et al. Image segmentation algorithms applied to wood defect detection. Computers and Electronics in Agriculture, n.41, n.1/3, p.157-179, 2003.

JOHnSON, R. A.; WICHERN, D. W. R. Applied Multivariate statistical analysis. 4.ed. Rio de Janeiro: Prentice-Hall, 1998. 816p.

KAUPPINEN, H. Development of a color machine vision method for wood surface inspection. 1999. 133f. Dissertation (M.S. in Electrical of Engineering) - University of Oulu, Oulu, Finlandia, 1999.
KHOURY JUNIOR, J. K. et al. Análise discriminante paramétrica para reconhecimento de defeitos em tábuas de eucalipto utilizando imagens digitais. Revista Árvore, v.29, n.2, p.299-309, 2005.

KLINE, D. E.; SURAK, C.; ARAMAN, P. A. Automated hardwood lumber grading utilizing a multiple sensor machine vision technology. Computers and Electronics in Agriculture, n.41,..1/3, p.139-155, 2003.

LEE, S.; ABBOTT, A. L.; SCHMOLDT, D. L. Surface shape analysis of rough lumber for wane detection. Computers and Electronics in Agriculture, n.41, n.1/3, p.121-137, 2003.

LEITE, H. G. et al. Determinação dos custos da qualidade em produção de mudas de eucalipto. Revista Árvore, v.29, n.6, p.955-964, 2005.

LU, Q. A real-time system for color sorting edge-glued panel parts. 1997. 118f. Dissertation (M.S. in Electrical of Engineering) - Faculty of the Virginia Polytechnic Institute, Blacksburg, Virginia, 1997.

MATLAB User's guide. The Math Works, 2000.

PULNIX America, 2005. Specifications of the Camera Link Interface Standard for Digital Cameras and Frame Grabbers. PULNix America. Disponível em: <http:// www.compumodules.com/pdf/ CameraLinkOfficial.pdf $>$. Acesso em: $17 \mathrm{fev}$. 2005. 
